\title{
Discussion on ecotourism management of Giant Panda National Park in China
}

\author{
Xiaoyu Duan $^{1, *}$, Shuhui Yang ${ }^{1}$ \\ ${ }^{1}$ College of Landscape Architecture, Sichuan Agricultural University, Chengdu 611130, China
}

\begin{abstract}
The Giant Panda National Park is one of the important contents in the construction of a natural reserve system based on national parks in China. It undertakes the responsibility of biodiversity conservation based on giant pandas, and takes into account functions such as recreation, science, and education. On the basis of protecting ecological integrity, the development of eco-tourism is an important issue to be considered in the construction of national parks. This paper combines the current status and trends of ecotourism development in national parks at home and abroad, and summarizes the advantages and existing problems of ecotourism in Giant Panda National Park, and discusses the development direction and construction content of ecotourism management.
\end{abstract}

\section{Introduction}

In 1990, the International Ecotourism Association (TIES) defined ecotourism as "responsible travel to natural areas that conserves the environment and sustains the wellbeing of local people" [1]. In 2015, TIES revised the definition of ecotourism, and its revised definition is "responsible travel to natural areas that conserves the environment, sustains the well-being of the local people, and involves interpretation and education" [2]. Three definitions of this definition are extremely important: "is non-consumptive/non-extractive', 'creates an ecological conscience', 'holds eco-centric values and ethics in relation to nature' [3]. Therefore, ecotourism is different from traditional tourism in that it emphasizes the equal exchange between man and nature [4]. It is a very ecoconscious way of tourism that is highly socially responsible for the appreciation of nature and the protection of nature. The Giant Panda National Park is a national park pilot area approved and established by the Chinese state. Ecotourism is one of the main forms of ecological experience and popular science education in the Giant Panda National Park. It has a certain development foundation in some tourist areas, but it has not yet formed a true form of ecotourism, lacking relevant qualification certification, ecotourism management and tourist behavior education and management. The construction target of the Giant Panda National Park is a demonstration area for biodiversity conservation, a pioneering area for ecological value, and a model area for world ecological education. As an important form of tourism and related stakeholders to participate in national park exchanges, ecotourism is particularly important for its standardized and reasonable tourism behavior and rational use and management of natural resources.

\section{The current situation and development trend of ecotourism in national parks}

\subsection{The current situation and development trend of ecotourism in national parks}

\subsubsection{Current status of ecotourism in foreign national parks}

There are a large number of national parks in the United States. Tourism is a pillar industry in many states in the United States, and it is also planned to become a global leader in the industry. The ecological tourism industry in the United States mainly has two forms: private operation and regional self-management. The eco-tourism area is managed by the state government and the local government. The relevant government agencies in the United States are responsible for the support and promotion of ecotourism. Ecotourism is mainly carried out in national parks and protected areas, and is consumeroriented. The United States has also added 'responsible travel' and 'responsible traveller' labels to ecotourism [5]. The ecotourism management in the United States is mainly reflected in ecotourism planning, education, supervision, policies and regulations. The sustainability of ecotourism depends on the protection of resources, the education of the public and operators, and good business planning and operations. Ecotourism activities vary by region, but most activities will focus on interactions with the natural environment. Based on extensive travel marketing experience, many states have provided ecotourism brochures for ecotourism entrepreneurs, established educational websites to promote education for

\footnotetext{
* Corresponding author: 13645273@qq.com
} 
tourists and operators, and established tourism management degrees at universities.

Costa Rica is a smaller sovereign country in Central America. Ecotourism is one of its pillar industries and a world-famous eco-tourism destination. As early as the 1970 s to the 2000s, Costa Rica was the world's leading ecotourism destination, rich in biodiversity and pleasant climate, and considered to be a pioneer in the implementation of real ecotourism [6]. There are 28 national parks and multiple protected areas in Costa Rica, which together account for $28 \%$ of the entire country [7]. While thinking about how to protect the beautiful natural environment, Costa Rica has passed more than 30 environmental-related laws and warned tourists, residents and operators to comply with relevant environmental protection regulations when entering national parks or nature reserves. Strict legislation has evaded people's destructive behavior, and strict law enforcement has ensured the ecological integrity protection of the region.

Australia is the first country in the world to implement an ecotourism strategy. The country has rich tourism resources, and the government attaches great importance to the eco-tourism and environmental protection of national parks and protected areas. Its management is undertaken by the federal government and the state governments. The focus of the Australian ecotourism business is on green tourism education for visitors and encourages visitors to minimize their carbon footprint. This business promotes the sustainability of tourism and is conducive to the development of local communities and the inheritance and protection of culture and heritage. The country also has a world-leading and well-developed ecocertification program that requires tour operators to at least obtain an eco-certification at the "ecotourism" level. ECO Certification certifies specific natural tourism products (tourism, accommodation, attractions) and identifies true natural and ecotourism operators to ensure that certified products provide high quality nature-based tourism experiences [8]. ECO Certification has three certification levels, namely 'Nature Tourism', 'Ecotourism' and 'Advanced Ecotourism'. Among them, "Advanced Ecotourism" represents Australia's leading and most innovative eco-tourism product. It uses the resources intelligently while minimizing the impact on the environment. It is also a model for everyone to learn [8]. It is worth mentioning that most national parks and ecotourism operators in other protected areas have passed the eco-certification of the Ecotourism Australia.

\subsubsection{Development trend of ecotourism in foreign national parks}

In recent years, international ecotourism has developed rapidly, and national parks are the key areas for ecotourism. Some universities and educational institutions have opened ecotourism-related majors and courses based on market demand. For example, ACS Distance Education's eco-tourism guide training and related stakeholders vocational training, learning organization and development of eco-tourism services, including eco-tourism activities plan, legal issues, ecological interpretation, destination understanding, accommodation and catering, tourism safety, etc. And the Applied Ecotourism and Outdoor Leadership at Mount Royal Mount University in Alberta, Canada is dedicated to cultivating ecotourism planners.

The global ecotourism market is divided by the United States, Canada, Mexico, Germany, France, Britain, Italy, Russia, China, India, Australia, Africa and other countries and regions. In the "web of science ${ }^{\mathrm{TM}}$ core collection" 2005-2015 panel data, the United States is the region with the highest number of ecotourism research, followed by China, Australia, Canada, the United Kingdom and other countries. And their research hotspots mainly include tourism resources, tourism activities, tourists' environmental education, community management, and ecological resources protection, etc. [9]. The 2018 Ecotourism Outlook summarizes important elements related to the development of ecotourism in the United States in recent years, including carefully planned and researched trips, voluntary and conservation based trips, culturally based tourist attractions, nature based sightseeing, animal friendly and a variety of outdoor and adventure travel activities, local specialties and organic products while travelling [3]. At this stage, most travel consumers are more inclined to personally more realistic travel experiences. However, excessive tourism in some tourist hotspots is still a problem that needs to be focused on. TIES believes that over-tourism does not stem from eco-tourism, which is a positive solution to this growing crisis [10].

\subsection{Overview of China's national park ecotourism}

\subsubsection{The current status of ecotourism in Chinese national parks}

China's exploration of ecotourism began in the 1990s. Both academics and government administrations attach great importance to the development of ecotourism [11]. However, China's eco-tourism has been in the form of shouting slogans for a long time. Most of the vigorous development of eco-tourism is based on the promotion of tourism industry development, and the environmental protection is relatively weak, causing ecological damage and environmental pollution in some areas. In 2016, the National Ecotourism Development Plan (2016-2015) clearly pointed out that protection should be placed first in the development of ecotourism, and the relationship between resource protection and utilization should be properly handled [12]. At present, China is deploying and actively implementing ecological civilization as a national strategic system, promoting the construction of a natural protection land system with national parks as the main body, and promoting the harmonious coexistence between man and nature. The part of environmental protection in ecotourism has gradually been taken seriously. In October 2019, the National Park Administration of China stated in a press conference that China will end the national park system pilot, summarize and evaluate the experience, and formally establish a number of national parks by 2020 
[13]. The construction of China's national parks is still in its infancy, and 10 national park pilot projects have been launched, including Sanjiangyuan, Northeast Tiger \& Leopard, Giant Panda, Qilian Mountain, Shennongjia, Wuyishan, Potatso, etc. And they have achieved initial results. The content construction of the eco-tourism part of the national park is still under investigation.

\subsubsection{The development trend of ecotourism in Chinese national parks}

The scope of the Chinese National Park includes some of the original scenic spots, geological parks, forest parks and other tourist attractions, which are the main areas for ecotourism. Some tourist attractions have already begun to explore the development of regional eco-tourism before the construction of national parks. At present, they have their own unique development model. The Potatso National Park in Shangri-La, Yunnan was officially established in 2007. It is one of the first national park system pilots in the country and the first national park established in mainland China. Since the establishment of Potatso National Park, the tourism development area and tourism activities have been strictly controlled. Through scientific planning, construction and management, it implements the development and utilization of $2.3 \%$ of the park area, achieving effective protection of the area of 97.7\% [14]. Potatso National Park adheres to the concept of ecology and environmental protection and implements "minimum" tourism infrastructure construction. For example, the only restaurant in the area and seven environmentally friendly public toilets use solar-powered technology. The tourism revenue of the park is first used to achieve the integrity protection of the park ecosystem, and secondly to deal with the relationship between surrounding communities and stakeholders [15]. The surrounding communities and stakeholders enhance their awareness of environmental protection through ecological benefits.

The next stage of China's national park construction will be the pilot construction assessment and the official establishment of the national park. The detailed planning, construction, management and legislation of the national park will be continuously improved. Its traditional utilization area, popular science recreation area, and entrance community are all important areas for ecotourism. According to the different characteristics and protection contents of each national park, the national park pays more attention to the ecological and environmental protection of the facilities while promoting the construction of tourism infrastructure, bio-protection monitoring and facilities monitoring. There are a large number of tourists in China. The number of tourists and the control of tourists' behavior and ecotourism education will become the focus and difficulty of the national park ecotourism management.

\section{The current status of ecotourism in Giant Panda National Park}

\subsection{The advantages of ecotourism in Giant Panda National Park}

Ecotourism related to giant pandas is no longer a new thing. In September 2002, the National Park Administration (the former State Forestry Administration of China) officially approved the development of the first national nature reserve, the Sichuan Wolong National Nature Reserve, and adopted the Sichuan Wolong National Nature Reserve Ecotourism Plan [16]. In January 2017, the General Office of the Communist Party and the General Office of the State Council of the People's Republic of China issued an overall plan for the establishment of a national park system [17]. The Panda National Park pilot project was built on the existing protected areas such as nature reserves, forest parks and wetland parks. In August of the same year, the Panda National Park System Pilot Implementation Plan (20172020) was issued [18], clarifying that the government will rely on the resources, facilities and influence advantages of the Giant Panda National Park to develop national culture and eco-tourism. It will also promote the development of related industries such as panda cultural products and special agricultural products processing, and promote the economic transformation and development of surrounding areas and counties. By the end of 2018, the annual direct income of ecotourism in Sichuan Province was 114.474 billion yuan, an increase of $19 \%$ over 2017 [19]. Among them, rural ecological tourism was 86.7 billion yuan, accounting for more than $70 \%$ of the total. Sichuan has received 335 million tourists, and its main destinations are forest parks, nature reserves, wetlands and ecological villages. The ecological tourism of the Giant Panda National Park is not only the characteristics and key of Sichuan's eco-tourism, but also an opportunity to develop characteristic rural tourism and implement rural revitalization. The advantages of eco-tourism in Giant Panda National Park are mainly reflected in the following four aspects:

- China's national policy actively promotes the construction of eco-tourism in the Giant Panda National Park, and is committed to establishing an eco-education display model area, making the Giant Panda National Park a benchmark and business card for environmental education and ecological display in the world.

- The love of giant pandas at home and abroad and the extensive attention to the construction of the Giant Panda National Park at this stage provide a good market condition for the development of eco-tourism in the Giant Panda National Park.

- The Giant Panda National Park involves a number of ethnic minority aborigines and diverse ethnic cultures, providing cultural resources for the development of characteristic ecotourism.

- The construction of the entrance community of the Giant Panda National Park and the development of tourism in the recreation area are actively promoted based on the existing transportation system, and the accessibility is strong. 


\subsection{Problems in ecotourism in Giant Panda National Park}

The Giant Panda National Park was built late, and it was still in the transition period from the pilot stage to the official establishment. Ecotourism related to giant pandas has been developed for some time relying on some nature reserves and scenic spots. However, the generalization of ecotourism in the early stage has made it a term that only attracts tourists, which is equivalent to the consumption of ordinary tourism. For example, the tourism activities of the Tangjiahe Nature Reserve have had a partial impact on the survival of giant pandas. Before the development of protected areas (2000) and after development (2012), giant pandas showed significant avoidance effects on tourist walking routes [20]. Ordinary tourism is obviously not satisfied with the ecological protection requirements of nature reserves. At this stage, the Giant Panda National Park has placed the Giant Panda Nature Reserve in the scope of protection, and the true meaning of "ecotourism" has been taken seriously. At present, there are four main problems in the ecotourism of Giant Panda National Park: - At present, China lacks laws and regulations related to ecotourism.

- The eco-tourism market in Giant Panda National Park is immature, and the ecological awareness of tourists, communities and stakeholders is weak.

- The Giant Panda National Park lacks ecotourism qualification.

- The government, the public, and operators do not pay enough attention to the tourism value of other rare animals and plants and novel forms of tourism.

\section{Conclusions and suggestions}

The eco-tourism market of Giant Panda National Park is still in the stage of struggling development. Eco-tourism management and related planning and construction are in the process of exploration. It requires the joint efforts of the government, the public, relevant stakeholders and scholars from all walks of life. The government is advancing the planning and construction of the entrance community of the Giant Panda National Park and the ecological restoration project of the general control area in the park. The intensity of development in different areas of the national park and surrounding areas is different, and the planning of ecotourism projects is also different. The general control area is a key area for implementing ecological restoration, improving habitat quality and building ecological corridors, and distributing indigenous people. The entrance community is composed of the relocation of indigenous people in some parks and the integration of in-situ areas. These two regions are the main places for carrying out natural education and ecological experience services. How to transform traditional tourism forms to develop eco-tourism has become the focus of tourism development in the current Giant Panda National Park.

In 2019, the China (Sichuan) Giant Panda International Ecotourism Festival was held in Chengdu, aiming at practicing the concept of "scientific leadership, ecological protection, and green development", building a platform for international exchange and cooperation of giant pandas, cultivating ecological and cultural industries, and shaping a giant panda eco-tourism brand, in order to continue to promote the vigorous development of the giant panda protection industry. The opening ceremony of the eco-tourism festival, the Sichuan Forestry and Grassland Bureau also released three giant panda boutique tourism routes and the first batch of 10 "ecotowns" featuring giant pandas [21]. The establishment of ecotourism certification system is one of the effective tools to resolve the contradiction between national park protection and development. At this stage, the construction of the entrance community of the Giant Panda National Park is in full swing, and some nature reserve tourist routes are in operation. The ecotourism certification system needs to be established.

China's ecotourism has developed rapidly in recent years, but it lacks the follow-up and close cooperation of legal regulation. Many developments have been exposed in the development of eco-tourism. As a specific land area for the protection and rational utilization of natural resources, the Giant Panda National Park has positive significance for the conservation of biodiversity in China. As an important part of the economic and social development of the Giant Panda National Park and the surrounding underdeveloped regions, ecotourism requires relevant legislation to ensure the ecological integrity and sustainable development of national parks. The legislative content can detail the protection and management of wildlife and the specific constraints on tourists' behavior, as well as the management and restrictions on ecotourism operators. The implementation of the legislation can be implemented in conjunction with the implementation of certain rewards and punishments, subsidy policy measures.

China's eco-tourism education started relatively late, and most of them are still in the research stage and the reference to foreign excellent cases. Public education is implemented less and still in the exploration stage. Promoting ecotourism mass education is conducive to ensuring the sustainability of ecotourism, weakening the contradiction between regional protection and development, and strengthening the ecological integrity protection of the Giant Panda National Park. The ecotourism education of Giant Panda National Park, on the basis of protection education for giant pandas, should pay attention to the content education of national park ecological integrity protection, tourist and operator behavior guidance, rational use of resources and restrictions. In addition, the implementation of specific content may include providing the public with a publicity manual for national park environmental protection, providing tourists with ecotourism behavior guides, guiding tourists and operators to sign eco-tourism norms agreement, and enhancing the communication education of ecotourism behavior through the media. At the same time, compared to the single traditional tour mode, the Giant Panda National Park can promote new environmentally friendly tourism models by drawing on new forms of international tourism such as personal adventure, outdoor adventure, hiking, wild bird cognition, 
and plant science. It is conducive to attracting tourists and taking into account the natural science education function of the public.

\section{Acknowledgments:}

This study was supported by the 2017 Sichuan Agricultural University double support program (03572602), the 2018 Sichuan Agricultural University double support program (03573245) and the 2019 Sichuan Agricultural University Social Science Research Project (2019PTYB04)

\section{References}

1. M. M. Khan, Annals of Tourism Research 24, 988991 (1997)

2. TIES, 2015. https://ecotourism.org/news/tiesannounces-ecotourism-principles-revision/. (accessed on 5 November 2019)

3. K. S. Bricker, https://tra.com/wpcontent/uploads/2018/11/Ecotourism-Outlook2018.pdf. (accessed on 31 October 2019)

4. Y. J. Zhang, Y. D. Xu, Q.Y. Jia, Tourism Science 31, 51-64 (2017). ( in Chinese)

5. A. Stronza, W. H. Durham, Ecotourism and conservation in the Americas (Cromwell Press, The Trowbridge, 2008)

6. M. Honey, Ecotourism and sustainable development: Who owns paradise? (Island Press, The Washington, 2008)

7. R. V. Sanchez, Journal of Park and Recreation Administration 36, 115-128 (2018)

8. Ecotourism Australia, https://www.ecotourism.org.au/assets/DestinationCertification/2019-Program-Essentials-ECODestination-Certification-compressed.pdf. (accessed on 30 October 2019)

9. H. Zhang, Y. Q. Sun, J. H. Si, Journal of Natural Resources 32, 342-352 (2017). ( in Chinese)

10. TIES, 2019. https://ecotourism.org/news/ecotourism-is-thesolution-to-overtourism/. (accessed on 6 November 2019)

11. S.Y. Zhang, J. M. Liu, H. Zhu, T. Li, Progress in Geography 37, 1201-1215 (2018). ( in Chinese)

12. the Central People's Government of the People's Republic of China, 2016. http://www.gov.cn/gongbao/content/2017/content_5 194900.htm. (accessed on 5 November 2019)

13. National Park Administration, 2019. http://www.forestry.gov.cn/main/5497/20190712/16 0955437275945.html. (accessed on 30 October 2019)

14. National Park Administration, 2017. http://www.forestry.gov.cn/main/72/content1026042.html. (accessed on 5 November 2019)
15. Z. H. Gou, Yunnan Pictorial 3, 26-27 (2012). ( in Chinese)

16. H. W. Yin, China Society Periodical 08S, 28-31 (2012). ( in Chinese)

17. The People's Government of Sichuan Province, 2017. http://www.sc.gov.cn/10462/12771/2017/8/9/10430 252.shtml. (accessed on 5 November 2019)

18. The People's Government of Sichuan Province, 2017. http:/www.sc.gov.cn/10462/12771/2017/8/17/1043 0953.shtml. (accessed on 5 November 2019)

19. the Central People's Government of the People's Republic of China, 2019. http://www.gov.cn/xinwen/2019-

01/20/content 5359437.htm. (accessed on 5 November 2019)

20. G. Liu, M. H. Gong, T. P. Guan, T. P. Chen, H. X. Li, Y. Zhang, T.Y. Zhou, Chinese Journal of Zoology 51, 724-733 (2016) . ( in Chinese)

21. The People's Government of Sichuan Province, 2019. http://www.sc.gov.cn/10462/14721/14727/14748/20 19/9/30/12ad52e2668a4048ba38269baf0afde4.shtml. (accessed on 5 November 2019) 